\title{
A Revolução dos Bichos: Uma Análise Fílmica do Papel das Fontes de Poder em Situações de Conflito
}

\author{
Animal Farm: A Film Analysis of the Role of Power Supplies in Conflict Situations
}

\author{
Diego de Queiroz Machado ${ }^{1 *}$, Editinete André da Rocha Garcia ${ }^{1}$, Augusto César de Aquino Cabral ${ }^{1}$, \\ Fátima Regina Ney Matos ${ }^{2}$
}

${ }^{1}$ Universidade Federal do Ceará (UFC), Ceará, Brasil.

${ }^{2}$ Universidade Potiguar, Rio Grande do Norte, Brasil.

\section{INFO ARTIGO}

\section{Palavras-chave:}

Poder;

Conflito;

Estudo observacional;

Narrativa fílmica;

Revolução dos Bichos.

\begin{tabular}{l}
\hline A R T I C L E IN F O \\
\hline Keywords: \\
Power, \\
Conflict, \\
Observational study, \\
Filmic narrative, \\
Animal Farm.
\end{tabular}

\footnotetext{
* Correspondência para autor: diegoqueirozm@yahoo.com.br (Machado, D.Q.), editinete@hotmail.com (Garcia, E.A.R), cabral@ufc.br (Cabral, A.C.A.), fneymatos@globo.com (Matos, F.R.N.).
}

DOI: dx.doi.org/10.21714/1679-18272019v17n2.p120-136

1679-1827 (C) 2019 Gest@o.org.

\begin{abstract}
RESUMO
Situando-se dentro da abordagem foucaultiana de poder e tendo em vista avançar no exame das relações de poder em um sistema social, este estudo tem como objetivo analisar o impacto das principais fontes de poder em situações de conflito. Para tanto, optou-se pela utilização de uma abordagem qualitativa, fundamentada na técnica de estudo observacional em linguagem fílmica, tendo como fonte de dados narrativos o filme A Revolução dos Bichos. Dentre as fontes de poder apresentadas, destacou-se o papel dos símbolos de poder como elementos ratificadores e fortalecedores das relações de poder estabelecidas, sendo utilizados, desse modo, por humanos e animais. Além do papel dos símbolos, foram também considerados como fontes de relações de poder a autoridade formal, o controle do conhecimento e da informação, a habilidade de lidar com incertezas, controle da tecnologia, controle das contra-organizações e o poder que já se tem, tendo em vista que podem ser fortemente observados no filme analisado.

A B S T R A C T
It is situating in Foucault's approach to power and in order to advance the
examination of power relationships in a social system, this study aims to
analyze the impact of the main sources of power in conflict situations.
Therefore, was chose to use a qualitative approach, based on observational
technique in film language, and as a source of narrative data the movie
Animal Farm. Among the sources of power presented, the role of the symbols
of power as ratifying and strengthening elements of established power
relations was highlighted, being used, therefore, by humans and animals. In
addition to the role of symbols, formal authority, the control of knowledge
and information, the ability to deal with uncertainty, control of technology,
control of counter-organizations, and the power already held, considering that
they can be strongly observed in the analyzed film.
\end{abstract}




\section{Introdução}

Definido por Foucault (1979, p. 176) como "uma guerra prolongada por diversos meios", o poder é considerado pelo referido autor sob uma perspectiva dinâmica, que não o analisa como uma simples propriedade ou coisa adquirida, mas como uma prática derivada de um sistema de relações. Dessa forma, não se pode considerar o poder como um atributo localizado ou concentrado em instituições ou indivíduos específicos, mas algo que "está em toda parte; não porque englobe tudo, e sim porque provém de todos os lugares" (FOUCAULT, 1976, p. 89), funcionando como uma rede disciplinar em que nenhum ator é proprietário.

Abordagens anteriores, como a de Hobbes (1651), definiam o poder como elemento representado através de meios naturais (força, beleza, inteligência, etc.) ou instrumentos adquiridos (riqueza, reputação, amigos e sorte). Consequentemente, para este e outros cientistas sociais, como Marx (1867) e Nietzsche (1881), o Estado seria o detentor em supremacia do poder, ao reunir em si os poderes de vários indivíduos, atuando como uma só pessoa.

Apesar de permanecer forte ao longo dos últimos séculos, essa abordagem tradicional do poder como qualidade estática, que divide determinados grupos sociais e indivíduos entre dominadores e dominados, mostra-se altamente simplista e ingênua. Em suma, o que se assevera, a partir dos trabalhos de Foucault $(1975,1976,1979)$ é que há a necessidade de analisar o poder como uma relação, relação esta que é "ambígua, reversível, [e] que luta belicosamente por controle, dominação e vitória” (FOUCAULT, 1979, p. 66). Tais relações de poder são responsáveis por conduzir situações de luta e disputa, funcionando como uma atividade estratégica, na qual o corpo é a realidade concreta mais atingida, sendo controlado em seu comportamento tendo em vista o adestramento e aprimoramento dos indivíduos (FOUCAULT, 1975).

Em abordagem semelhante, Bourdieu (1991) também se refere ao poder como emergente das relações de lutas, mesmo que simbólicas, entre diversos grupos para a imposição da sua própria definição do mundo social. O poder, chamado pelo autor de simbólico, está em constituir o dado pela enunciação, fazendo ver e crer na medida em que é reconhecido. Esse poder, na visão de Arendt (1970), só se dá de forma coletiva, a partir de grupos, nunca individualmente.

Em trabalho mais recente, Morgan (2009), ao explorar aspectos referentes a questões de interesse, conflito e poder dentro do universo das organizações, apresenta diversas fontes de poder que seriam responsáveis por conferir a determinados indivíduos ou grupos a capacidade de solucionar ou superar conflitos. A análise dessas fontes, contudo, é apresentada pelo autor de forma didática e pontual, sem explorar o impacto da sua atuação conjunta ou mesma a possibilidade de influências recíprocas entre algumas dessas fontes.

Situando-se dentro da abordagem foucaultiana de poder e tendo em vista avançar no exame das relações de poder em um sistema social a partir da apreciação da diferentes fontes apresentadas por Morgan (2009), este estudo tem como objetivo analisar o impacto das principais fontes de poder em situações de conflito.

Para tanto, optou-se pela utilização de uma abordagem qualitativa, fundamentada na técnica de estudo observacional em linguagem fílmica, descrita por Machado e Matos (2012). Diferentemente da utilização de narrativas fílmicas em sala de aula apenas para cunho didático, esta metodologia de estudo observacional utilizada considera os dados narrativos, mesmo que alegóricos ou fíctícios, como fontes de dados para a pesquisa por ser como que uma representação da própria sociedade (MACHADO; MATOS; MESQUITA, 2017).

Como fonte de dados narrativos, foi selecionado o filme A Revolução dos Bichos (1999) que, em uma fábula representativa da corrupção do poder na União Soviética comandada por Josef Stalin, narra a história de um fazendeiro cruel e explorador de animais que se vê em meio a uma revolução quando, revoltados com os constantes maus tratos, os animais tomam posse da fazenda.

\section{Fontes de Poder em uma Abordagem Dinâmica}

Nesta seção, tendo em vista possibilitar uma fundamentação teórica do fenômeno e conceitos em estudo, além de servir de suporte para análise dos dados narrativos, são apresentados aspectos relevantes acerca das fontes 
de poder, apresentadas por Morgan (2009).

\subsection{Autoridade formal}

Segundo Weber (1999, p. 188), a autoridade pode ser definida como um "poder de mando e dever de obediência". Para ser formal ou legítima, toda autoridade precisa estar fundamentada algum elemento de legitimação, sendo eles: tradição; lei; ou carisma. Vasconcelos (2004, p. 204), assim as caracteriza: " $A$ autoridade tradicional, que é oriunda das tradições e dos costumes [...]; a autoridade carismática, que advém das propriedades de liderança [...]; a autoridade racional-legal, que surge em função da norma abstrata e da obediência a uma organização formal e despersonalizada".

Dando como exemplo a ascensão do fascismo no século XX, Crochik (1998) assevera que o enfraquecimento de uma autoridade tradicional pode permitir a sua substituição por outro tipo de autoridade. O que se percebe, então, é uma inter-relação entre esses três tipos de autoridades, as quais, apesar de apresentadas por Weber (1999) em seu estado puro, dificilmente podem ser encontradas isoladas em um sistema social, como mostra os estudos de Fabian (2006) em um movimento religioso. Dessa forma, é importante reconhecer o papel que cada uma dessas formas de autoridade ou dominação desempenha em grupos e sociedades, sendo a autoridade tradicional e a racional-legal apresentadas por Weber (1999) mais em momentos de continuidade ou manutenção das atuais características de um sistema social, enquanto a autoridade carismática se mostra como importante em contextos de mudanças ou revolução.

Ademais, há que se considerar a importância da utilização ética desses tipos de autoridade. Como demonstrado por Reis (1990), a autoridade legal, quando evolui para formas de opressão pelo excesso burocrático, tende a ser compelida para modelos mais voltados para a democracia. Sendo assim, qualquer autoridade, quando em seu formato legítimo, é condição muitas vezes indispensável para o sucesso de um sistema social, principalmente quando exercida por agentes do Estado (CARBONE, 1991).

\subsection{Controle sobre recursos escassos}

Barney (1991, p. 101) afirma serem os recursos "todos os bens, capacidades, processos organizacionais, atributos, informações, conhecimentos, etc. controlados por uma empresa que permitem a ela conceber e implementar estratégias que melhorem sua eficiência e eficácia". Complementando a classificação de Penrose (1959) que, anteriormente, já havia tratado das empresas como um conjunto de recursos produtivos, sejam eles recursos materiais ou humanos, Barney (1991) incorpora atributos de valor competitivo a esses recursos, sendo estes atributos: valor; raridade; imitabilidade; e substituibilidade, que posteriormente foi substituído por organização (BARNEY; HESTERLY, 2007). A presença desses atributos, portanto, caracterizariam o grau de escassez de um recurso.

No contexto das relações de poder, estudos clássicos como os de Pfeffer e Salancik (1974) e Pfeffer e Moore (1980) apresentam uma análise de sua configuração tendo como foco, exclusivamente, o controle dos recursos financeiros, que põem em destaque a ação da alta-gestão na concentração de poder. Porém, com a ampliação dessa análise para os demais tipos de recursos, que comumente se encontram distribuídos ao longo de toda a estrutura organizacional, permite perceber também o papel de outros indivíduos ou grupos na disputa pelo controle desses recursos escassos.

\subsection{Uso da estrutura organizacional, regras e regulamentos}

Sendo consideradas por Quinello (2007) como um reflexo do processo de institucionalização, a estrutura organizacional, bem como suas regras e regulamentos, é inicialmente considerada a partir de uma abordagem estratégica, tendo em vista a obtenção de uma máxima eficácia operacional, como apresentado pelos estudos de Chandler (1962). Definida por Vasconcellos e Hemsley (2003, p. 3) como "o resultado de um processo através do qual a autoridade é distribuída, as atividades desde os níveis mais baixos até a Alta Administração são especificadas e um sistema de comunicação é delineado", essa estrutura, no entanto, pode ser constantemente utilizada como um instrumento político, seja de dominação dos chefes sobre os subordinados, ou mesmo de resistência dos subordinados com as chefias (MORGAN, 2009). Tal embate no âmbito das estruturas organizacionais é reforçado principalmente pelas novas configurações das equipes trabalho e desenho em rede, como apresentado por Sacomano Neto e Escrivão Filho (2000) e Olivares (2002).

\subsection{Controle do processo de tomada de decisão}


Sendo constituído tanto por elementos racionais quanto por aspectos intuitivos e criativos (SOLINO; ELAOUAR, 2001), o processo de tomada de decisão pode ser analisado sob diferentes abordagens. Neste sentido, Gontijo e Maia (2004) apresentam uma análise desse processo que vai desde uma abordagem de total racionalidade até uma abordagem mais política, que considera os jogos de poder existentes dentro das relações organizacionais. Para o entendimento dos aspectos de controle do poder, têm-se a assertiva de Gutierrez (1999, p. 33): "Na organização tradicional, as decisões são tomadas por uma elite decisória que se perpetua no poder através de um amplo processo de alianças, provocando distanciamento dos macrobjetivos e perda de informação". Assim, o controle sobre método, participantes e duração e objetivos de uma tomada de decisão aparece como determinante para os resultados alcançados neste processo.

\title{
2.5 Controle do conhecimento e da informação
}

Ao afirmar que "informação não é conhecimento", Baccega (1998, p. 8) faz uma distinção desses dois constructos, atrelando informação a um processo mais de repasse e reprodução de dados e o conhecimento a um processo mais reflexivo e criativo. Em um contexto de gestão, Tarapanoff (2006, p. 28) também ressalta sua distinção, afirmando: "No que tange ao conhecimento, o foco da gestão da informação é voltado para o gerenciamento do conhecimento explícito, enquanto a gestão do conhecimento preocupa-se com o gerenciamento do conhecimento tácito". Essa relação entre gestão, conhecimento e informação, no entanto, vai muito além da estruturação de fluxos e redes de dados.

Seguindo a lógica do pensamento atribuído ao filósofo inglês Francis Bacon de que conhecimento é poder, Toffler $(1980,1990)$ assevera ser o conhecimento uma fonte de poder capaz de punir, premiar, persuadir e até mesmo transformar indivíduos, dando ao seu detentor a possibilidade de contornar situações desagradáveis. Em uma sociedade onde a informação e o conhecimento são ativos indispensáveis para o sucesso de organizações e demais grupos sociais, seu controle acaba por legitimar o posicionamento de indivíduos especializados (BOFF; ABEL, 2005).

\subsection{Controle dos limites e fronteiras}

Conforme Fontenelle (2007, p. 69), “a noção de fronteira organizacional está vinculada ao estabelecimento de limites para fora (imagem externa)". Tal definição se fundamenta em uma visão tradicional da organização em termos formais, que as definem como "entidades estruturais, dotadas de fins explícitos, de uma estrutura formalizada e de um corpo de regras concebidas com o propósito de modelar os comportamentos tendo em vista a realização desses fins" (BOUDON, 1995, p. 392). Essas fronteiras, contudo, não se limitam à separação entre os ambientes interno e externo da organização, estando também presentes dentro da própria organização.

Neste contexto, esses indivíduos que atuam entre diferentes grupos sociais, sendo chamados por Aguiar (2007) atores ativos, são os grandes influenciadores dos demais indivíduos por atuarem nas diversas iniciativas de comunicação que alimentam a estrutura social, sendo também capazes de controlar essas informações. Destarte, como asseverado por Morgan (2009), o poder desses indivíduos está no exercício de integrar ou isolar grupos a partir do controle de seus limites.

\subsection{Habilidade de lidar com incertezas}

Tendo como objetivo explicar o total significado do termo incerteza, Keynes (1973, p. 113-114) afirma:

\begin{abstract}
Por conhecimento "incerto", deixe-me explicar, eu não pretendo meramente distinguir o que se sabe com certeza do que é apenas provável. O jogo de roleta não está sujeito, nesse sentido, à incerteza [...] A expectativa de vida é apenas ligeiramente incerta. Até mesmo o clima é apenas moderadamente incerto. O sentido em que estou usando o termo é aquele em que a perspectiva de uma guerra européia é incerta, ou o preço do cobre e a taxa de juros daqui a vinte anos... Sobre essas questões, não há base cientifica em que se possa formar qualquer probabilidade calculável. Nós simplesmente não sabemos.
\end{abstract}

Dessa forma, entende-se que a incerteza em sua definição keynesiana está além de quaisquer cálculos probabilísticos, que podem ser aplicados em jogos de roleta, expectativa de vida e previsões meteorológicas, mas que em casos de real incerteza são de impossível mensuração. Dentro das organizações, Morgan (2009) 
distingue as incertezas entre ambientais (de fora da organização) e operacionais (de dentro da organização), destacando a capacidade de desafiar ambos os tipos de incerteza como uma importante fonte de poder.

Ao ressaltar inúmeros estudos que tiveram como intuito medir a incerteza, Lombardi e Brito (2010) acabam por defender que a sua presença deve ser analisada não em termos ambientais, mas em termos individuais e subjetivos, sendo, portanto, uma consequência da racionalidade limitada defendida por Simon (1955). Assim, pode-se considerar que o impacto da incerteza, mesmo sendo imprevisível, pode ser minimizado pelo comportamento de determinados indivíduos.

\title{
2.8 Controle da tecnologia
}

Figueiredo (2009) define tecnologia como um corpo específico de conhecimento, retido por pessoas e organizações ao longo de sua experiência. Proença (1996) a considera como uma fonte de poder para o aumento das capacidades humanas. Sobre essa relação entre tecnologia e poder, Feenberg (2010, p. 69) afirma:

\begin{abstract}
A tecnologia é uma das maiores fontes de poder nas sociedades modernas. Quando as decisões que afetam nosso dia-a-dia são discutidas, a democracia política é inteiramente obscurecida pelo enorme poder exercido pelos senhores dos sistemas técnicos: líderes de corporações, militares e associações profissionais de grupos como médicos e engenheiros. Eles possuem muito mais controle sobre os padrões de crescimento urbano, o desenho das habitações, dos sistemas de transporte, a seleção das inovações, sobre nossa experiência como empregados, pacientes e consumidores do que o conjunto de todas as instituições governamentais da sociedade.
\end{abstract}

Deste modo, reconhece-se os controladores dos sistemas técnicos como os detentores de grande poder em um sistema social. O exercício dessas tecnologias como forma de controle sobre os indivíduos é o que Foucault (1976) denominou biopoder. Contudo, esse controle não é estático já que, como observado por Clegg (1992), é exatamente essa introdução de novas tecnologias que pode alterar as relações de poder entre os indivíduos e grupos ou trabalhadores e administradores, sendo, portanto, um elemento altamente dinâmico nesta movimentação.

\subsection{Alianças interpessoais, redes e controle da organização informal}

Caracterizada por Witt (1969, p. 205) como fruto da "interação decorrente do funcionamento da entidade", a organização informal é vista, em comparação com a organização formal, como uma realidade não apenas racional, mas social. Também no âmbito da gestão, Macedo (1999, p. 94) as define como "estruturas autoorganizantes que, respondendo em grande parte pela capacidade de as organizações lidarem com os problemas imprevistos, configuram-se como instrumentos importantes ao enfrentamento dos desafios associados à sociedade da informação". Sua importância, segundo Loiola, Bastos, Queiroz e Silva (2009), estaria na sobrevivência organizacional em ambientes complexos, de mudanças constantes, elevado grau de incerteza e com muitos concorrentes pelo poder.

Fundamentando-se na perspectiva dialética da análise dos relacionamentos proposta por Hinde (1997), Ventorini e Garcia (2004) afirmam ser o poder não uma propriedade do indivíduo, mas do relacionamento. Dessa forma, em uma rede de relações, o poder dificilmente consegue ser absoluto, estando sempre limitado a determinados contextos. Além disso, sobre a percepção que os indivíduos têm do poder dentro dessas redes interpessoais, Ventorini e Garcia alegam (2004, p. 128): “Quanto maior for a confiança no parceiro, mais distorcida será a percepção do seu poder. Outras propriedades do relacionamento, como o compromisso endógeno e a intimidade, também podem distorcer a percepção da distribuição de poder". Sendo assim, ressalta-se que uma análise das relações de poder dentro de sistemas sociais deve ir além da consideração do poder em si, incorporando elementos da percepção sobre esse mesmo poder.

\subsection{Controle das contra-organizações}

Contra-organizações é a denominação dada por Morgan (2009) às instituições que se organizam como um bloco de poder para rival coordenado por forças opostas às forças já estabelecidas, sendo os sindicatos o exemplo principal no âmbito das organizações. Como apontado por Bastos e Costa (1998), o poder dos sindicatos reside na sua capacidade de dividir parte do comprometimento dos indivíduos, que se inserem tanto no contexto da organização empregadora quanto no contexto dessas contra-organizações. Em 
consequência dessa relação, aspectos como a efetividade, desempenho, rotatividade e absenteísmo são comumente afetados.

Também ressaltando o poder dos sindicatos sobre os indivíduos, Limoncic (1999, p. 130) afirma que "os sindicatos passaram a ser vistos, ainda que por limitados círculos industriais, como instrumentos disciplinadores da mão-de-obra". Contudo, o que se assevera é muito mais uma posição de contínua articulação de interesses dentro do sistema organizacional e aplicação de sistemas de barganha contra o poder organizacional (PRATES, 1996). Assim, os sindicatos, bem como outros exemplos de contra-organizações, como associações de consumidores, cooperativas e grupos sociais, atuam como forças opostas que objetivam estabelecer um equilíbrio nas relações de poder entre seus agentes.

\subsection{Simbolismos e administração do significado}

“Com sua propensão para criar símbolos, o homem transforma inconscientemente objetos ou formas em símbolos (conferindo-lhes assim enorme importância psicológica) e lhes dá expressão" (JAFFÉ, 2008, p. 232). Partindo dessa assertiva acerca da administração inconsciente de significado que o indivíduo atribui aos elementos de sua vida, é possível reconhecer a importância que os símbolos têm nas relações sociais. $\mathrm{O}$ simbolismo, segundo Sperber (1978), vai além de um processo simples de resgate de memórias, atuando como elemento de interpretação das informações gravadas.

No âmbito das organizações sociais, Wood Jr. (2000, p. 23) ressalta a questão dos simbolismos afirmando: "Na virada do milênio, as organizações estão se transformando em 'reinos mágicos', em que o 'espaço simbólico' é ocupado pela retórica, pelo uso de metáforas e pela manipulação dos significados". Tal assertiva faz referência a todos os modelos de organizações, sendo mais fortemente relacionada com as chamadas organizações de simbolismo intensivo, cujos ambientes apresentes quatro características principais: liderança simbólica como um estilo gerencial; inovações tratadas como eventos dramáticos; técnicas de gerenciamento da impressão aplicadas por líderes e liderados; e a presença de analistas simbólicos, que trabalham com atividades abstratas, dentro do grupo (WOOD JR., 2000).

Cohen (1978) considera o simbolismo e as relações de poder como elementos interdependentes, apesar de terem sido usualmente estudados separadamente pelos antropólogos sociais. Assim, reconhece-se a influência mútua que ambos exercer sobre o outro, de forma que as relações de poder se constituem símbolos em si mesmas, mas também são constantemente alteradas por novas representações simbólicas construídas por seus indivíduos: "Os símbolos são capazes de gerar relações de poder e de se converter em símbolos de poder” (DEL CASTILLO, 1989, p. 330).

\subsection{Gênero e administração das relações entre os sexos}

Os primeiros estudos em torno das relações de gênero tinham como foco aspectos exclusivamente biológicos, como aponta Giffin (1994), evoluindo posteriormente para a apreciação de elementos mais sociológicos e eminentemente políticos (MEYER, 2004). Neste sentido, apesar da disseminação de discursos igualitários, predominantes em sociedades ocidentais, ainda são muitas as diferenças que permeiam as representações de gênero. Steil (1997) aponta para tais diferenças como reflexo dos valores e sociais predominantes em um sistema social. Além disso, consideram-se poderosas as influências do discurso nas categorias de gênero já que, de acordo com Moore (2000, p. 17), "produzem homens e mulheres marcados por gênero, como pessoas que são definidas pela diferença". Tais diferenças "passam a se substituir, e as distinções codificadas entre elas se tornam o lugar principal de produção de efeitos mais gerais de poder" (MOORE, 2000, p. 29).

Para lidar com esses desequilíbrios de poder entre os gêneros, Morgan (2009) apresenta estratégias utilizadas por homens e mulheres, conforme quadro 1, que segue.

Quadro 1 - Estratégias usadas no relacionamento entre os sexos.

\begin{tabular}{|c|l|l|l|}
\hline \multicolumn{2}{|c|}{ ESTRATÉGIAS FEMININAS } & \multicolumn{2}{c|}{ ESTRATÉGIAS MASCULINAS } \\
\hline $\begin{array}{c}\text { Rainha } \\
\text { Elizabeth I }\end{array}$ & $\begin{array}{l}\text { Reina com mãos firmes, tendo sempre } \\
\text { que possível à sua volta homens dóceis. }\end{array}$ & O guerreiro & $\begin{array}{l}\text { Adotada por indivíduos muito } \\
\text { ocupados, sempre envolvidos em } \\
\text { batalhas dentro de uma organização. }\end{array}$ \\
\hline
\end{tabular}




\begin{tabular}{|c|c|c|c|}
\hline $\begin{array}{l}\text { A primeira } \\
\text { dama }\end{array}$ & $\begin{array}{l}\text { Está satisfeita por exercer o papel da } \\
\text { eminência parda. }\end{array}$ & O pai & $\begin{array}{l}\text { Utilizada para ganhar o apoio das } \\
\text { mulheres mais jovens que procuram } \\
\text { um mentor. }\end{array}$ \\
\hline $\begin{array}{l}\text { A mulher } \\
\text { invisível }\end{array}$ & $\begin{array}{l}\text { Tem um perfil inexpressivo: tenta } \\
\text { misturar-se com aqueles que estão à } \\
\text { sua volta, exercendo a sua influência } \\
\text { de todas as formas. }\end{array}$ & $\begin{array}{l}\text { Rei } \\
\text { Henrique } \\
\text { VIII }\end{array}$ & $\begin{array}{l}\text { Uso do poder absoluto para conseguir } \\
\text { aquilo que quer, atraindo e descartando } \\
\text { o apoio das mulheres de acordo com a } \\
\text { sua utilidade. }\end{array}$ \\
\hline A mãe & Consolida o seu poder sendo maternal. & O sedutor & $\begin{array}{l}\text { Usa sua sedução sexual para conseguir } \\
\text { apoio e favor das mulheres. }\end{array}$ \\
\hline $\begin{array}{l}\text { A mulher } \\
\text { liberada }\end{array}$ & $\begin{array}{l}\text { Joga dura e golpeia quando é golpeada. } \\
\text { Fala abertamente e sempre defende o } \\
\text { papel feminino. }\end{array}$ & $\mathbf{O} \mathbf{m}$ & $\begin{array}{l}\text { Baseada em vários tipos de } \\
\text { "comportamentos exibicionistas" que } \\
\text { visam atrair e convencer as mulheres } \\
\text { das suas proezas. }\end{array}$ \\
\hline A ams & $\begin{array}{l}\text { É a líder das mulheres. Este estilo é } \\
\text { especialmente bem sucedido quando } \\
\text { se pode construir uma forte coalizão, } \\
\text { colocando mulheres em posições de } \\
\text { influência. }\end{array}$ & $\begin{array}{l}\mathrm{O} \text { am } \\
\text { since }\end{array}$ & $\begin{array}{l}\text { Estratégia frequentemente utilizada } \\
\text { para conseguir uma forma de parceria } \\
\text { com colegas mulheres, seja como } \\
\text { confidentes, seja como fontes de } \\
\text { informação e orientação. }\end{array}$ \\
\hline Dalila & $\begin{array}{l}\text { Usa os seus poderes de sedução para } \\
\text { colocar os homens ao seu lado. }\end{array}$ & $\begin{array}{c}\text { O } \\
\text { menininho }\end{array}$ & $\begin{array}{l}\text { Utilizada para fazer "aquilo que se } \\
\text { quer" em situações difíceis. }\end{array}$ \\
\hline Joana d'Arc & $\begin{array}{l}\text { Usa o poder de uma causa e missão } \\
\text { comuns para transcender o fato de ser } \\
\text { mulher. }\end{array}$ & \multirow{2}{*}{$\begin{array}{c}\text { O porco } \\
\text { chauvinista }\end{array}$} & \multirow{2}{*}{$\begin{array}{l}\text { Usada por homens que se sentem } \\
\text { ameaçados pela presença das } \\
\text { mulheres. Caracteriza-se pelos vários } \\
\text { rituais de "degradação" que procuram } \\
\text { minar a posição da mulher e as suas } \\
\text { contribuições. }\end{array}$} \\
\hline A filha & $\begin{array}{l}\text { Encontra uma figura de pai pronto } \\
\text { para agir como orientador e mentor. }\end{array}$ & & \\
\hline
\end{tabular}

Fonte: adaptado de Morgan (2009).

Destarte, percebe-se que as diferenças entre os gêneros, ou melhor, as diferenças entre as representações construídas acerca dos gêneros tendem, em determinados momentos, a favorecer um em detrimento do outro. Portanto, a importância no reconhecimento dessa relação entre poder e gênero é que, nas palavras de Capelle, Melo, Brito e Brito (2004, p. 10), "permite-se a identificação de pontos de resistência a essas práticas ao longo das redes relacionais, capazes de romper (em alguns momentos) com os efeitos de poder produzidos, criando outros e reformulando as alianças existentes".

\subsection{Fatores estruturais que definem o estágio da ação}

Os fatores estruturais, conforme discutidos por Morgan (2009), dizem respeito ao contexto sobre o qual as relações de poder se desenvolvem. Dada a grande quantidade de fontes de poder disponíveis para acesso por parte dos diferentes agentes sociais, como as apresentadas anteriormente, seu desempenho e importância são, desse modo, influenciados por todo o contexto, histórico e mutável, no qual esses agentes se inserem.

Assim, os sistemas de poder são analisados "como estando sempre em um estado de fluxo e mudança qualitativa, na medida em que seus elementos constitutivos alteram seu comportamento em relação aos demais e ao ambiente extra-sistêmico" (FREEMAN, 1988, p. 4), em uma abordagem ecológica e evolucionista, na qual as mudanças do ambiente interferem no desempenho, ou neste caso, nas relações de poder, dos seus agentes. Como relatado por Kanter (1977, p. 196): “O poder sobe e desce com base em exigências complexas: a situação organizacional, as pressões do meio ambiente, as ações simultâneas dos outros".

\subsection{O poder que já se tem}

“As pessoas querem, sobretudo, mais poder" (REGO, 1992, p. 185). E para o alcance desse nível maior de poder, o próprio poder já detido pode ser uma grande fonte de poder. Nas palavras de Kanter (1977, p. 196): “Em termos do comportamento individual, o poder pelo menos tende a trazer mais poder, em ciclos ascendentes, e a falta de poder, a gerar mais falta de poder, num ciclo descendente".

Desenvolvendo estudos no âmbito das oligarquias locais da região nordeste do Brasil, Bursztyn (1985), 
discorre acerca das diferentes formas de concentração de poder, evidenciando a perpetuação e acumulação do poder nas mãos de poucos indivíduos. Essa característica centralizadora, contudo, não é suficiente para extinguir o desenvolvimento de novas relações de poder mais descentralizadas, criando estruturas de poder locais. Da mesma forma, Lemenhe (1996) também ressalta o exercício do poder como fonte de mais poder nas raízes dos poderes dos coronéis, analisando sua origem familiar e política, que se perpetua também a partir de uma herança simbólica da imagem do detentor do poder, no caso, o coronel.

Em suma, a partir da apresentação dessas fontes de poder, citadas por Morgan (2009), reconhece-se a complexidade dos elementos que permeiam as relações de poder. Aspectos internos dos grupos, como lideranças, redes impessoais e simbolismos, e aspectos externos, como as contra-organizações, fatores estruturais e incertezas, aparecem como estreitamente elencados, de forma que sua apreciação tende a contribuir mais quando feita em conjunto do que sob um ponto de vista isolado. Ademais, é essa mesma complexidade nas fontes de poder que fomentam as situações de conflito. Como narrado por Falcini (1993, p. 15): "Não havendo um foco natural do poder, o conflito flui naturalmente; outras vezes, existem duas ou mais concentrações de poder compatíveis entre si, resultando em conflito". Daí a importância de se considerar essas fontes de poder em situações de conflito.

\section{Metodologia da Pesquisa}

A linguagem narrativa do cinema é apresentada por Deleuze (2005) sob a perspectiva de uma semiologia do cinema. Nesse sentido, o autor assevera:

O fato histórico é que o cinema se constitui como tal tornando-se narrativo, apresentando uma história, e rechaçando as outras direções possiveis. A aproximação que se segue é que, a partir de então, as sucessões de imagens e até mesmo cada imagem, um único plano, são assimiladas a proposições, ou melhor, a enunciados orais: o plano considerado como o menor enunciado narrativo (DELEUZE, 2005, p. 37).

Dentro dessa perspectiva, este estudo se utiliza da linguagem fílmica tendo em vista responder ao seu objetivo geral de analisar o impacto das principais fontes de poder em situações de conflito. Enquadrando-se dentro de uma abordagem qualitativa, que visa "o estudo de um fenômeno situado no local em que ocorre, [...] procurando tanto encontrar o sentido desse fenômeno quanto interpretar os significados que as pessoas dão a eles" (CHIZZOTTI, 2006, p. 28), a narrativa foi utilizada como fonte de dados acerca das fontes de poder discutidas na fundamentação teórica. Dessa forma, os diversos planos componentes da história, com suas imagens, cenários, personagens e falas, foram analisados em profundidade. Nesta análise, foram seguidas as etapas propostas por Machado e Matos (2012) para este tipo de estudo, denominado estudo observacional em linguagem fílmica: construção da questão ou objetivo de pesquisa; busca e seleção da fonte de dados narrativos; visão geral da narrativa fílmica; decupagem dos dados (cenas e falas); fundamentação e interpretação teórica dos dados; produção do relatório final.

Ressalta-se que o pesquisador, neste caso, é classificado com observador não participante, procedendo à interpretação do discurso fílmico conforme descreve Orlandi (2010, p. 61):

Sem procurar eliminar os efeitos de evidencia produzidos pela linguagem em seu funcionamento e sem pretender colocar-se fora da interpretação - fora da história, fora da língua - o analista produz seu dispositivo teórico de forma a não ser vítima desses efeitos, dessas ilusões, mas a tirar proveito delas. E o faz pela mediação teórica.

Sendo assim, a teoria apresentada anteriormente se torna a lente pela qual a análise dos dados é feita. Neste sentido, ressalta-se o afirmado por Deleuze (2005, p. 331), que “uma teoria do cinema não é 'sobre'o cinema, mas sobre os conceitos que o cinema suscita, e que eles próprios estão relacionados com outros conceitos que correspondem a outras práticas". Ademais, nesta etapa de análise, utilizou-se o software de pesquisa qualitativa Atlas.ti (versão 6) como ferramenta de auxílio à análise dos dados narrativos, possibilitando não apenas o recorte das cenas cujas fontes de poder são identificadas e analisadas, mas a construção de relações entre essas diversas fontes.

Com relação ao método de análise dos dados coletados, o presente estudo utilizou a estratégia de 
fundamentação nas proposições teóricas. De acordo com Yin (2009), essa estratégia utiliza as bases teóricas para examinar os dados extraídos do estudo observacional, definindo o foco e orientando toda a análise do estudo. Dessa forma, foi possível a construção de um diálogo entre dados e teoria, apresentando na seção seguinte.

\section{A Revolução dos Bichos: Estudo Observacional}

A Revolução dos Bichos (1999) - Animal Farm, no original — é um filme britânico televisivo baseado na fábula homônima do escritor inglês George Orwell (2007), publicada inicialmente em 1945 no Reino Unido. Sobre sua concepção, narra Orwell (2007, p. 125): "Este livro começou a ser concebido, ou pelo menos sua ideia central, em 1937, mas só comecei a escrevê-lo no final de 1943". Sendo finalizado em apenas três meses, a publicação do livro, contudo, enfrentou dificuldades por se apresentar como uma sátira aos governos totalitários, principalmente ao do líder soviético Josef Stalin (SÁ, 2003). Nesta obra, conforme descrito por Sá e Soares (2005, p. 1), "Orwell descreve as relações de produção numa granja, administrada por um humano, na qual os bichos — submetidos a condições de trabalho miseráveis — se revoltam". Sua apreciação e análise são feitas em três atos, conforme segue.

\subsection{Ato I: O prelúdio da revolução}

A narrativa fílmica, contada em retrospectiva por uma de suas personagens, a cadela Jessie, tem início com um cenário de tempestade que cai sobre a paisagem da fazenda, e a seguinte narração:

Jessie: Era uma tempestade de condenação. Passamos anos escondidos da opressão;
escondidos dos espiões de Napoleão. Mas agora a natureza expurgava a doença. Eu
sempre soube que, como tudo construído em bases erradas, a fazenda ruiria um dia.
Finalmente, a espera terminara. O cimento venenoso que conservava reunido o sonho
maligno de Napoleão fora dissolvido. Podia sentir seu gosto na água. Eu era velha, estava
quase cega, mas ainda podia me lembrar.

Neste primeiro momento, as ideias reunidas no texto que abre a narrativa são importantes para a observação da lógica do conflito e das relações de poder a serem apresentadas ao longo do enredo. Ressaltase, inicialmente, a característica opressora do poder que se destacará nos eventos a serem apresentados, característica essa que, como apontado por Reis (1990), tende a enfrentar resistências, não se consolidando como um fenômeno perene. A própria metáfora presente na fala, que faz uma alusão da situação de conflito como uma tempestade, reforça esse aspecto efêmero do poder. Além disso, a caracterização desta relação de poder a partir de expressões negativas, como condenação, doença, venenoso e maligno, denota o não reconhecimento de sua legitimidade por parte dos indivíduos que lhe são sujeitos. Sendo essa legitimidade, segundo Weber (1999), fruto de tradições, leis ou carismas, há que se esperar uma ausência de tais condicionantes como o motivo da resistência observada.

A narrativa de Jessie tem como início o dia em que Mollie, a égua da fazenda Granja Solar (Manor Farm, no original), é trazida de volta pela família Pilkington, vizinhos para quem ela havia sido emprestada. No caminho para a fazenda, os filhos do casal Pilkington vão atirando pedras em diversos animais que estão ao longo da estrada, como ovelhas e porcos, ao que a Sra. Pilkington adverte: "Um dia, serão os porcos que virão brincar com vocês". Sob a perspectiva relacional do poder, essa advertência apresentada remete à abordagem de Foucault $(1975,1976,1979)$, que considera a reversibilidade das relações de poder entre os indivíduos envolvidos, em que os papéis de dominadores e dominados podem ser invertidos.

Em seguida, é apresentado o dono da Granja Solar, o Sr. Jones, que trabalhava na preparação de um campo para o plantio juntamente com o cavalo Boxer. Ressalta-se, nesta cena, o estado de embriaguez do $\mathrm{Sr}$. Jones, que tem dificuldades em se manter de pé, mas coloca a culpa no cavalo, que não estaria arando o campo em linha reta: “Boxer! Boxer! Ande em linha reta! Olhe aonde vai! Boxer! Linha reta! Linha reta! Cavalo idiota, faz tudo errado! [...] Cavalo estúpido. Você é um cavalo morto. Eu acabo com você!” (Sr. Jones). Assim, é apresentada a característica opressora da relação de poder do fazendeiro com seus animais, já apontada anteriormente. Ao presenciar essa cena de maus tratos e humilhação, Jessie salta sobre o fazendeiro, derrubando-o inconsciente. Nesse instante, Moisés, o corvo, que repreende Jessie, afirmando que "nenhum animal deve atacar uma pessoa". Tal regra apresentada vem a reforçar a relação de dominação entre o 
fazendeiro e os animais, corroborando com as discussões de Weber (1999) e Morgan (2009) acerca do papel das leis, regras e normas como fontes de poder.

Naquela mesma noite, todos os animais são convocados para uma reunião no celeiro pelo Velho Major, o porco ancião da fazenda, o mais velho dentre os animais, respeitado por todos e venerado pelos outros porcos como sendo "o mais sábio entre nós", carregando em si o poder oriundo da autoridade tradicional, como descrita por Vasconcelos (2004). Seu discurso é uma mistura de despedida e exortação:

Velho Major: Meus amigos, não acho que estarei entre vocês por muitos dias ainda. Tive uma vida longa e é meu dever passar para vocês aquilo que entendo como a natureza de nossa vida. Os animais nasceram para uma miserável, laboriosa e curta existência. Recebemos apenas comida o bastante para suportarmos fazer nosso trabalho. E, quando não somos mais úteis, somos mortos com extrema crueldade. E quem é o responsável pelo nosso sofrimento? O homem! O homem é nosso inimigo!

Esse discurso do Velho Major na reunião, que se inicia ressaltando o conhecimento armazenado pelo porco ancião ao longo de sua vida, remete ao papel do conhecimento e da informação como fonte de poder, como apontado por Toffler $(1980,1990)$, no que se refere ao seu potencial para persuadir indivíduos. Na narrativa, o conhecimento em relação às atitudes dos homens com os animais é, dessa forma, utilizado pelo porco como um reforço à sua autoridade formal-tradicional, legitimando o seu poder em relação aos demais animais, característica essa asseverada por Boff e Abel (2005), sendo também um catalisador para o advento da revolução.

Ao final de seu discurso, o porco ancião canta uma música, segundo ele, "sobre justiça e liberdade", sendo seguido por todos os outros animais. Segue a letra.

Velho Major: Animais do mundo, unam-se. Ergam-se e se preparem para a luta. Cedo ou tarde, chegará o dia em que venceremos o homem e seremos livres. Nossas pernas estão cansadas e doloridas. Nossos sonhos não serão frustrados e não ficaremos com o coração partido.

Observa-se, nesse momento, uma sintonia entre todos os animais da fazenda, que se organizam como uma unidade para enfrentar o poder do fazendeiro. Essa organização formada pelos animais adquire, assim, ca racterísticas das contra-organizações apresentadas por Morgan (2009), estruturando-se como um bloco de poder rival ao poder estabelecido, o poder dos seres humanos. Contudo, o movimento de revolução que se iniciara acaba por ser interrompido pela interferência do fazendeiro que, ao se aproximar do celeiro em que os animais estavam reunidos, acaba disparando acidentalmente sua arma, atingindo e matando o Velho Major. Diante da cena, a cadela Jessie se questiona: "Teria nossa revolução terminado antes mesmo de começar?".

A resposta a essa pergunta vem na manhã seguinte quando, reunidos em homenagem ao Velho Major, os animais declaram: "Não há recompensas após a morte. Só existe o aqui e o agora. Precisamos tornar essa vida melhor. Amigos, vamos sempre nos lembrar que o Velho Major morreu por nossa causa. Agora, devemos respeito a ele. Revolução!’. Assim, percebe-se na narrativa o fenômeno de substituição de autoridade, descrito por Crochik (1998), em que o enfraquecimento de uma autoridade formal, no caso a do Velho Major, é seguido da substituição por outro tipo de autoridade. Assevera-se, portanto, que o poder não desaparece com o indivíduo que o detinha, mas é transferido para outrem, reforçando suas características relacional e dinâmica.

\subsection{Ato II: Atos de revolução}

Nos dias que seguiram à morte do Velho Major, o Sr. Jones, envolvido nos problemas financeiros da fazenda, passa a beber dia e noite, abandonando o cuidado aos animais. Em uma noite, a falta de comida faz com que os animais invadam o celeiro em busca de alimento. Quando o fazendeiro e dois empregados escutam os barulhos e vão até o celeiro, são atacados pelos animais e expulsos da fazenda, indo buscar refúgio com os vizinhos. Sobre esse fato, o Sr. Pilkington afirma para o Sr. Jones: "O tratamento a seus animais os levou a tomar o poder. Uma revolução que pode se espalhar pelas fazendas". Essa advertência final se remete à discussão apresentada por Kanter (1977), que considera o próprio poder como fonte de mais poder, estando, portanto, sempre em movimento, sendo acumulado ou perdido. Assim, o temor é de que ao conquistar o poder sobre a Granja Solar, os animais decidam estender seu poder para as demais fazendas da região. 
$\mathrm{Na}$ Granja Solar, os animais começam a se organizar a partir de novas relações de poder. Como narrado pela cadela Jessie: "Finalmente a fazenda pertencia a nós. Estávamos livres e podíamos viver sem medo. Bola de Neve nos mostraria o caminho". Bola de Neve, a quem Jessie se refere em sua fala, é um dos porcos da fazenda que, em sua primeira cena como novo líder dos revolucionários, é mostrado tentando ler vários livros sobre conflitos políticos, como A Defesa de Berlim, de Jean Edward Smith. Essa característica do porco Bola de Neve, de buscar o acúmulo de novos conhecimento para lidar com os desafios da fazenda, acaba por legitimar seu poder em relação aos demais animais, como defendiam Boff e Abel (2005). Além disso, a preocupação do porco em aprender novas habilidades, como as técnicas de ordenha das vacas, também acaba por fortalecer seu poder, como observado por Proença (1996) e Feenberg (2010).

Bola de Neve, então, dá um novo nome à fazenda, reescrevendo o letreiro existente no portão de entrada, trocando o nome de Granja Solar para Fazenda Animal. Esse novo nome se apresenta, dessa forma, como o símbolo da conquista dos animais do poder sobre a fazenda, representando as novas relações de poder existentes, nas quais os seres humanos estão excluídos. Assim, corrobora-se a tese defendida por Cohen e Del Castillo (1989), em que os símbolos e as relações de poder são elementos interdependentes, sendo que os símbolos acabam por se converter em representações dessas relações.

Além disso, com a saída dos seres humanos da fazenda, os animais invadem a casa-sede, onde estão presentes vários objetivos que simbolizam o poder dos homens sobre os animais, como estofados de couro de animal e a sala do matadouro, com vários pedaços de carnes de animais pendurados, tendo inclusive a cabeça do Velho Major em um armário. Contudo, com exceção da sala de corte, que os animais decidem limpar, enterrando os restos de animais mortos, eles decidem preservar a casa-sede da forma como foi deixada, "como um museu", nas palavras de um dos porcos, adotando-a como um símbolo do antigo poder dos homens, não mais existente.

Outro símbolo da revolução é elaborado por Bola de Neve, como as regras que, a partir de então, deveriam conduzir as ações dos animais da Fazenda Animal. Tomando como base as ideias do Velho Major, Bola de Neve escreveu as seguintes regras, batizadas de "Princípios do Animalismo":

Um: Quem anda sobre duas pernas é inimigo. Dois: Quem anda sobre quatro patas ou tem asas, é amigo. Três: Nenhum animal deve usar roupas. Quatro: Nenhum animal deve dormir numa cama. Quinto: Animais não devem beber álcool. Sexto: Nenhum animal deve matar qualquer outro animal. E o mais importante, em sétimo: Todos os animais são iguais.

Essas regras foram escritas na parede externa do celeiro, à vista de todos os animais. Assim como a placa colocada na entrada da fazenda, esse painel também se apresenta como um símbolo do poder dos animais sobre os humanos, nos moldes da autoridade racional-legal, descrita por Vasconcelos (2004). De fato, toda essa construção e preocupação dos animais com representações do antigo poder dos humanos e da sua atual supremacia asseveram com as ideias de Sperber (1978), Wood Jr. (2000) e Jaffé (2008), que destacam a importância desses símbolos nas relações sociais. Por fim, o último símbolo dos animais é uma bandeira que, nas palavras de Bola de Neve, é a "bandeira de liberdade", chamada de "O Casco e O Chifre".

Contudo, enquanto Bola de Neve procurava conduzir os animais a partir das ideias do Velho Major, outro porco chamado Napoleão começou a se aproveitar dos demais animais para controlar a fazenda. Buscando inicialmente o apoio dos cachorros da fazenda, Napoleão passa a gerenciar a colheita, exigindo que os outros animais trabalhem sem descanso. O porco Napoleão, dessa maneira, apresenta perante os cachorros aspectos uma relação de poder legitimada pelo carisma, como descrito por Weber (1999). Sua justificativa inicial para essa sobrecarga de trabalho era de que, segundo Napoleão, a colheita seria para os animais " $O$ ponto de honra: colher mais depressa do que a raça humana". Assim, mesmo que em um primeiro momento os animais se sintam livres em poder fazer todo o trabalho da fazenda sem o comando dos homens, logo percebem a nova exploração sob a qual são colocados.

Neste momento, o Sr. Jones e o Sr. Pilkington, juntamente com outros fazendeiros da região, decidem investigar a atual situação da fazenda, tendo em vista encontrar meios para retomar o seu controle. O primeiro passo, segundo o Sr. Pilkington, é conseguir informações sobre o que está acontecendo na fazenda. Assim, os homens decidem colocar um aparelho de escuta no celeiro, para espionar os animais. Como já apontado 
anteriormente, novamente a importância das informações é destacada como fundamental em situações de conflitos, como apontado por Toffler $(1980,1990)$. Essa fonte de poder também é destacada em uma cena que se segue a essa da reunião dos homens, em que os animais são apresentados reunidos no celeiro tendo aulas do idioma dos homens com Bola de Neve, que diz: "Educação é conhecimento, e conhecimento e poder".

Trabalhando sob as ordens de Napoleão, os animais começam a perceber, contudo, que a divisão da produção não é feita igualmente para todos. Os porcos se aproveitam da atividade de gerenciamento da fazenda para ficar com o leite e as maçãs produzidos. Assim, os animais começam a se sentir insatisfeitos, ameaçando o poder estabelecido por Napoleão sobre as atividades da fazenda. Para se manter no poder, Napoleão coloca o aparelho de televisão do Sr. Jones no celeiro, com o intuito de distrair os animais, oferecendo a televisão em troca do leite e das maçãs produzidos. Destaca-se, neste ponto, a preocupação de Napoleão em manter o controle sobre os produtos da fazenda, que são os principais recursos escassos da organização e funcionam como moedas de troca, aumentando a concentração do poder como abordam Pfeffer e Salancik (1974) e Pfeffer e Moore (1980). Além disso, a utilização da televisão como uma estratégia de manutenção e fortalecimento das relações de poder existentes entre os porcos e os outros animais corrobora com a tese de Clegg (1992) em relação ao uso de tecnologias no exercício das relações de poder entre trabalhadores e administradores.

Mesmo sem terem sido incomodados pelos fazendeiros desde que tomaram o controle da fazenda, os animais pensam na possibilidade de uma ação dos homens contra a Fazenda Animal. Sendo assim, temendo que, mais cedo ou mais tarde, houvesse uma retaliação por parte dos homens, os animais, sob o comando dos porcos, preparam uma estratégia de defesa no caso de um ataque dos fazendeiros. Essa ação dos fazendeiros de fato acontece, mas, diferente dos animais, que já estavam preparados para um ataque, os homens são surpreendidos pela ação organizadas dos bichos, e são novamente expulsos da fazenda. Desse modo, o poder sobre a fazenda é mantido pelos animais, como fruto de sua habilidade em lidar com esse tipo de evento, que se configura como uma incerteza, como definida por Keynes (1973) e Morgan (2009).

Com a derrota definitiva dos fazendeiros, os conflitos de poder passam ocorrer entre os próprios animais, no caso, entre os porcos Napoleão e Bola de Neve. Ao discordar de um projeto de construção de um moinho de vento, proposto por Bola de Neve, Napoleão se utiliza do poder acumulado junto aos cachorros fazendo com que esses expulsem Bola de Neve da fazenda. Dessa maneira, o poder acumulado por Napoleão acaba por facilitar a conquista de mais poder junto aos animais, nos moldes da espiral crescente de poder citada por Kanter (1977) e com a consequente concentração de poder apontada por Bursztyn (1985). Sem mais oposições declaradas, Napoleão passa a ocupar o antigo espaço do Velho Major no celeiro, dando início ao seu governo da fazenda.

\subsection{Ato III: A contra-revolução}

Com o controle da fazenda concentrado nas mãos de Napoleão, os demais animais são impedidos de participar das decisões da fazenda, sendo incumbidos apenas do trabalho pesado. Esta nova fase da Fazenda Animal é narrada pela cadela Jessie da seguinte forma: "Então começou o trabalho pesado. Foi um processo lento e cansativo. Éramos vigiados o tempo todo. [...] À noite voltávamos para casa, cansados e famintos".

Contando sempre com o apoio de Garganta, um porco especialista em convencer os outros animais com discursos pomposos, Napoleão decide mudar vários dos mandamentos criados pelo Velho Major, passando a morar na sede da fazenda, se comportando como um ser humano. Os quatro últimos Princípios do Animalismo são, então, reescritos da seguinte forma: "Quatro: Nenhum animal dormirá em cama com lençóis. Quinto: Nenhum animal beberá álcool em excesso. Sexto: Nenhum animal matará outro animal sem motivo. Sétimo: Todos os animais são iguais, mas alguns são mais iguais que os outros".

Mesmo com alguns animais não concordando essas alterações nos princípios, os porcos não encontram resistência. Chama a atenção neste aspecto as ovelhas da fazenda, que se comportam com excessivo espírito de submissão, aceitando imediatamente todas as palavras de Napoleão e Garganta como verdades inquestionáveis. Assim, a narrativa acaba por dar ao gênero feminino, representado em grande parte pelas ovelhas, uma conotação mais submissa, semelhante às características da filha, estratégia feminina apresentada por Morgan (2009).

A exceção, contudo, é a cadela Jessie, que atua dentro da fazenda conforme a estratégia de mulher 
invisível, apontada por Morgan (2009), exercendo sua influência entre os animais, mas sem chamar a atenção dos porcos. Neste sentido, por manter o diálogo com praticamente todos os grupos animais da fazenda, as relações de poder de Jessie cruzam as chamadas fronteiras organizacionais, caracterizadas por Fontenelle (2007), podendo ser considerada o agente mais ativo dentro dos limites da fazenda. No entanto, ao iniciar uma prática de comércio com os antigos fazendeiros, que haviam desistido de tentar retomar o controle da Fazenda Animal, Napoleão se torna também um agente atuante nos limites e fronteiras organizacionais, não internas, mas externas, sendo outro agente ativo, como definido por Aguiar (2007).

Com a criação do comércio com os fazendeiros, Napoleão aumenta a exploração do trabalho dos animais da fazenda. Além disso, os porcos passam a acumular para si a maior parte da comida, deixando os outros animais famintos. Em suma, Napoleão e Garganta passam a se comportar como o Sr. Jones, bebendo álcool em excesso e explorando o trabalho dos animais. Em consequência dessa exploração, o cavalo Boxer, considerado o animal mais forte da fazenda, adoece e é entregue pelos porcos para ser sacrificado. Desolados com a morte de Boxer e diante da situação de miséria em que se encontravam, os animais, sob a liderança de Jessie, que usa a estratégia feminina da mãe (MORGAN, 2009), fogem da fazenda e passam a viver escondidos. Sua narração desse movimento de espera é a seguinte:

\begin{abstract}
Jessie: A vida não era livre em nosso esconderijo. As estações iam e vinham e nós esperávamos. Os anos passaram e nós envelhecemos, e esperamos por um final muito aguardado. Esperamos que a ganância e crueldade de Napoleão sangrassem a fazenda até a morte. Agora, com a chegada da tempestade, veio o primeiro sinal do fim da nossa espera. Era hora de voltar para aquele lugar que antes continha tanta esperança. [...] Meu coração se partiu. Mas sempre há sobreviventes. As muralhas caíram, as feridas cicatrizaram e a vida continua.
\end{abstract}

Assim, a falência das estruturas de poder estabelecidas é apresentada pela narrativa ao seu final como um processo natural. De fato, esta característica é ressaltada por Morgan (2009) ao discorrer acerca dos fatores estruturais como fonte de poder. Neste sentido, como apontado por Kanter (1977) e Freeman (1988), as relações de poder se caracterizam por mudanças constantes, principalmente em consequência do ambiente em que estão inseridas. Dessa forma, aquilo que era tido em um sistema como importante fonte de poder, em dado momento pode deixar de ser, como ocorre na narrativa, que se encerra com a chegada de uma nova família de fazendeiros à Fazenda Solar/Animal.

\title{
5 Considerações Finais
}

Tendo como objetivo analisar o impacto das principais fontes de poder em situações de conflito, esse trabalho se utilizou da metodologia de estudo observacional em linguagem fílmica, sendo possível a análise das quatorze fontes de poder, apontadas por Morgan (2009), em um sistema social.

A análise do filme escolhido como fonte de dados narrativos, A Revolução dos Bichos (1999), desenvolveu-se a partir da análise de cenas, personagens, símbolos e falas presentes na narrativa, onde se pôde identificar a presença das fontes de poder apresentadas inicialmente. Desse modo, ao longo dos eventos que constituem a narrativa, o papel de cada uma dessas fontes de poder foi destacado. Muitas vezes insidioso, uma das artimanhas do poder é imiscuir-se, disfarçando-se por meio de subterfúgios, como é inicialmente a relação que Napoleão estabelece com os outros animais, diferentemente do Sr. Jones, que usava a força para alcançar resultados.

Dentre as fontes de poder apresentadas, destacou-se o papel dos símbolos de poder como elementos ratificadores e fortalecedores das relações de poder estabelecidas, sendo utilizados, desse modo, por humanos e animais. Além do papel dos símbolos, foram também considerados como fontes de relações de poder a autoridade formal, o controle do conhecimento e da informação, a habilidade de lidar com incertezas, controle da tecnologia, controle das contra-organizações e o poder que já se tem, tendo em vista que podem ser fortemente observados no filme analisado.

Considerando a análise do filme, pode-se concluir com a afirmação de Foucault $(1975$, p. 91) quando afirma "que lá onde há poder há resistência", desenvolvendo-se "o poder a partir de inúmeros pontos e em meio a relações desiguais e móveis", o que o caracteriza como efêmero e passageiro. 


\section{Referências}

AGUIAR, S. Redes sociais na internet: desafios à pesquisa. In: CONGRESSO BRASILEIRO DE CIÊNCIAS DA COMUNICAÇÃO, 30, 2007. Anais... Santos, SP: Sociedade Brasileira de Estudos Interdisciplinares da Comunicação, 2007.

ANIMAL FARM. Direção: John Stephenson. Produção: Greg Smith e Robert Halmi. Intérpretes: Kelsey Grammer; Ian Holm; Julia Louis-Dreyfus; Patrick Stewart; Julia Ormond; Paul Scofield; Pete Postlethwaite; Peter Ustinov. Roteiro: Alan Janes, Martyn Burke e George Orwell. Música: Richard Harvey. Reino Unido: Hallmark Films. 1 DVD (91 min). color., legendado.

ARENDT, H. On violence. New York: Hancourt, 1970.

BACCEGA, M. A. Conhecimento, informação e tecnologia. Comunicação \& Educação, v. 4, n. 11, p. 7-16, 1998.

BARNEY, J. B. Firm resources and sustained competitive advantage. Journal of Management, v. 17, n. 1, p. 99-120, 1991.

BARNEY, J. B.; HESTERLY, W. S. Administração estratégica e vantagem competitiva. São Paulo: Pearson Prentice Hall, 2007.

BASTOS, A. V. B.; COSTA, P. R. Os vínculos do trabalhador com a organização e o sindicato: padrões de comprometimento e valores relativos ao trabalho. Organizações \& Sociedade, v. 5, n. 13, p. 87-105, 1998.

BOFF, L. H.; ABEL, M. Autodesenvolvimento e competências: o caso do trabalhador de conhecimento como especialista. In: RUAS, R.; ANTONELLO, C. S.; BOFF, L. H. Aprendizagem organizacional e competências. Porto Alegre: Bookman, 2005.

BOUDON, R. Tratado de sociologia. Rio de Janeiro: Jorge Zahar, 1995.

BOURDIEU, P. Language and symbolic power. Cambridge: Harvard University Press, 1991.

BURSZTYN, M. O poder dos donos: planejamento e clientelismo no nordeste. 2. ed. Petrópolis: Vozes, 1985. CAPPELlE, M. C. A.; MELO, M. D.; BRITO, M. J. M.; BRITO, M. D. Uma análise da dinâmica do poder e das relações de gênero no espaço organizacional. RAE eletrônica, v. 3, n. 2, p. 1-17, 2004.

CARBONE, P. P. Fenômenos ligados ao autoritarismo organizacional: a visão crítica de guerreiro ramos sobre organização autocrática. Revista de Administração Pública, v. 25, n. 3, p. 85-100, 1991.

CHANDLER, A. D. Strategy and structure: chapters in the history of the industrial enterprise. Cambridge, MA: M.I.T. Press, 1962.

CHIZZOTTI, A. Pesquisa qualitativa em ciências humanas e sociais. Petrópolis, RJ: Vozes, 2006.

CLEGG, S. R. Tecnologia, instrumentalidade e poder nas organizações. Revista de Administração de Empresas, v. 32, n. 5, p. 68-95, 1992.

COHEN, A. Antropología política: El análisis del simbolismo en las relaciones de poder. In: LLOBERA, J. R. (Org.). Antropología política. Barcelona: Anagrama, 1979.

CROCHIK, J. L. Os desafios atuais do estudo da subjetividade na Psicologia. Psicol. USP, v. 9, n. 2, p. 6985, 1998.

DEL CASTILLO, A. M. Simbolismo y poder: un estudio antropológico sobre compadrazgo y priostazgo en una comunidad andina. Barcelona: Anthropos, 1989.

DELEUZE, G. A imagem-tempo. São Paulo: Braziliense, 2005.

FABIAN, J. A prática etnográfica como compartilhamento do tempo e como objetivação. Mana, v. 12, n. 2, 
p. 503-520, 2006.

FALCINI, P. Organizações como configurações naturais do poder. Revista de Administração de Empresas, v. 33, n. 1, p. 6-15, 1993.

FEENBERG, A. Racionalização subversiva: tecnologia, poder e democracia. In: NEDER, R. T. (Org.). A teoria crítica de Andrew Feenberg: racionalização democrática, poder e tecnologia. Brasília: Observatório do Movimento pela Tecnologia Social na América Latina / CDS / UnB / Capes, 2010.

FIGUEIREDO, P. N. Gestão da inovação: conceitos, métricas e experiências de empresas no Brasil. Rio de Janeiro: LTC, 2009.

FONTENELLE, I. A. Construção e desconstrução de fronteiras e identidades organizacionais: história e desafios do McDonald's. Revista de Administração de Empresas, v. 47, n. 1, p. 60-70, 2007.

FOUCAULT, M. História da Sexualidade I: a Vontade de Saber. Rio de Janeiro: Edições Graal, 1976.

FOUCAUlT, M. Microfísica do Poder. Rio de Janeiro: Edições Graal, 1979.

FOUCAULT, M. Vigiar e Punir. Petrópolis: Editora Vozes, 1975.

FREEMAN, C. Introduction. In: DOSI, G.; FREEMAN, C.; NELSON, R.; SILVERBERG, G.; SOETE, L. L. (Eds.). Technical change and economic theory. London: Pinter Publishers, 1988.

GIFFIN, K. Gender violence, sexuality and health. Cadernos de Saúde Pública, v. 10, n. 1, p. 146-155, 1994.

GONTIJO, A. C.; MAIA, C. S. C. Tomada de decisão, do modelo racional ao comportamental: uma síntese teórica. Cadernos de Pesquisa em Administração, v. 11, n. 4, p. 13-30, 2004.

GUTIERREZ, G. L. Gestão comunicativa: maximizando criatividade e racionalidade. Rio de Janeiro: Qualitymark, 1999.

HINDE, R. A. Relationships: a dialectical perspective. Hove, UK: Psychology Press, 1997.

HOBBES, T. O Leviatã. São Paulo: Martins Editora, 2008. (Publicado originalmente em 1651).

JAFFÉ, A. O simbolismo nas artes plásticas. In: JUNG, C. G. (Org.). O homem e os seus símbolos. Rio de Janeiro: Nova Fronteira, 2008

KANTER, R. M. Men and women of the corporation. New York: Basic Books, 1977.

KEYNES, J. M. The general theory and after: defence and development. London: MacMillan, 1973.

LEMENHE, M. A. Família, tradição e poder: o (caso) dos coronéis. São Paulo: Annablume, 1996.

LIMONCIC, F. Do pacto nacional à globalização: Estado e sindicato na regulação do capitalismo norteamericano. Revista de História Regional, v. 4, n. 1, p.129-146, 1999.

LOIOLA, E.; BASTOS, A. V. B.; QUEIROZ, N.; SILVA, T. D. Dimensões básicas de análise das organizações. In: ZANELLI, J. C.; BORGES-ANDRADE, J. E.; BASTOS, A. V. B. (Orgs.). Psicologia, organizações e trabalho no Brasil. Porto Alegre: Artmed, 2009.

LOMBARDI, M. F. S.; BRITO, E. P. Z. Incerteza subjetiva no processo de decisão estratégica: uma proposta de mensuração. Revista de Administração Contemporânea, v. 14, n. 6, p. 990-1010, 2010.

MACEDO, T. M. B. Redes informais nas organizações: a co-gestão do conhecimento. Ciência da Informação, v. 28, n. 1, p. 94-100, 1999.

MACHADO, D.; MATOS, F. R. N. (Orgs.). Estudos observacionais em linguagem fílmica. Curitiba: Editora CRV, 2012. 
MACHADO, D.; MATOS, F. R. N.; MESQUITA, R. F. O poder da linguagem fílmica. In: MATOS, F. R. N.; MESQUITA, R. F.; MACHADO, D. (Orgs.). Estudos observacionais em linguagem fílmica: ética e poder. Curitiba: Editora Prismas, 2017.

MARX, K. O Capital: Crítica da economia política. São Paulo: Boitempo Editorial, 2013. (Publicado originalmente em 1867).

MEYER, D. E. Teorias e políticas de gênero: fragmentos históricos e desafios atuais. Rev. Bras. Enferm., v. 57 , n. 1, p. 13-18, 2004.

MINTZBERG, H. The organization as political arena. Journal of Management Studies, v. 22, p. 133-154, 1985.

MOORE, H. Fantasias de poder e fantasias de identidade: gênero, raça e violência. Cadernos Pagu, v. 14, p. 13- 44, 2000.

MORGAN, G. Imagens da Organização. São Paulo: Atlas, 2009.

NIETZSCHE, F. W. Aurora: Reflexões Sobre os Preconceitos Morais. Petrópolis: Editora Vozes, 2008. (Publicado originalmente em 1881).

OLIVARES, J. E. F. Negociação para configurar o desenho da estrutura organizacional em rede. Caderno de Pesquisas em Administração, v. 9, n. 3, p. 13-26, 2002.

ORLANDI, E. P. Análise de discurso: princípios e procedimentos. 9. ed. Campinas, SP: Pontes Editores, 2010.

ORWELL, G. A revolução dos bichos. São Paulo: Companhia das Letras, 2007.

PENROSE, E. T. The theory of the growth of the firm. New York: Wiley, 1959.

PFEFFER, J. Power in organizations. Cambridge, MA: Bellinger Publishing, 1981.

PFEFFER, J.; MOORE, W. L. Power in university budgeting: a replication and extension. Administrative Science Quarterly, v. 25, n. 4, p. 637-653, 1980.

PFEFFER, J.; SALANCIK, G. R. Organizational decision making as a political process: the case of a university budget. Administrative Science Quarterly, v. 19, n. 2, p. 135-151, 1974.

PRATES, A. A. P. Sindicato: organização e interesses na sociedade capitalista avançada. Revista Brasileira de Ciências Sociais, v. 1, n. 2, 1996.

PROENÇA, R. P. C. Aspectos organizacionais e inovação tecnológica em processos de transferência de tecnologia: uma abordagem antropotecnológica no setor de alimentação coletiva. 1996. Tese (Doutorando em Engenharia) - Universidade Federal de Santa Catarina, Florianópolis, 1996.

QUINELLO, R. A teoria institucional aplicada à administração: entenda como o mundo invisível impacta na gestão dos negócios. São Paulo: Novatec Editora, 2007.

REGO, F. G. T. Cultura, Poder, Comunicação e Imagem. São Paulo: Cengage Learning, 1992.

REIS, E. P. Opressão burocrática: o ponto de vista do cidadão. Revista Estudos Históricos, v. 3, n. 6, p. 161$179,1990$.

SÁ, M. G. O poder, a política e os bichos de Orwell: um ensaio sobre a revolução dos bichos. Revista Eletrônica de Gestão Organizacional, v. 1, n. 2, p. 69-71, 2003.

SÁ, M. G.; SOARES, G. J. V. Reflexões sobre poder e controle nas Organizações da Economia Solidária (OES): um olhar à luz dos bichos de Orwell. Cadernos EBAPE.BR, v. 3, n. 2, p. 1-13, 2005. 
SACOMANO NETO, M.; ESCRIVÃO FILHO, E. Estrutura organizacional e equipes de trabalho: estudo da mudança organizacional em quatro grandes empresas industriais. Gestão \& Produção, v. 7, n. 2, p. 136-145, 2000 .

SIMON, H. A. A behavioral model of rational choice. Quarterly Journal of Economics, v. 69, p. 99-188, 1955. SOLINO, A. S.; EL-AOUAR, W. A.O processo de tomada de decisões estratégicas: entre a intuição e a racionalidade. Cadernos de Pesquisa em Administração, v. 8, n. 3, p. 15-26, 2001.

SPERBER, D. El simbolismo en general. Barcelona: Anthropos, 1978.

STEIL, A. V. Organizações, gênero e posição hierárquica: compreendendo o fenômeno do teto de vidro. Revista de Administração da Universidade de São Paulo, v. 32, n. 3, p. 62-69, 1997.

TARAPANOFF, K. Informação, conhecimento e inteligência em corporações: relações e complementaridade. In: TARAPANOFF, K. (Org.). Inteligência, informação e conhecimento em corporações. Brasília, DF: IBICT, UNESCO, 2006.

TOFFLER, A. Powershift: knowledge, wealth, and violence in the 21st century. New York: Bantam Books, 1990.

TOFFLER, A. The third wave. New York: Bantam Books, 1980.

VASCONCELLOS, E.; HEMSLEY, J. R. Estrutura das organizações: estruturadas tradicionais, estruturas para inovação, estrutura matricial. 4. ed. São Paulo: Pioneira Thomson Learning, 2003.

VASCONCELOS, F. C. Racionalidade, autoridade e burocracia: as bases da definição de um tipo organizacional pós-burocrático. Revista de Administração Pública, v. 38, n. 2, p. 199-220, 2004.

VENTORINI, B.; GARCIA, A. Relacionamento interpessoal: da obra de Robert Hinde à gestão de pessoas. Revista Psicologia, v. 4, n. 2, p. 117-143, 2004.

WEBER, M. Economia e sociedade: fundamentos da sociologia compreensiva. Brasília, DF: Editora UnB, 1999. (Publicado originalmente em 1922).

WITT, A. Importância e aproveitamento da organização informal. Revista de Saúde Pública, v. 3, n. 2, p. 203 $212,1969$.

WOOD JR., T. Organizações de simbolismo intensivo. Revista de Administração de Empresas, v. 40, n. 1, p. 20-28, 2000.

YIN, R. K. Case study research: design and methods. 4. ed. Thousand Oaks: Sage, 2009. 